\title{
Emotion Recognition and Traffic-Related Risk-Taking Behavior in Patients with Neurodegenerative Diseases
}

\author{
Nils S. van den Berg ${ }^{1,2, *}$ () , Fransje E. Reesink ${ }^{2}$, Edward H.F. de Haan ${ }^{1}$, Hubertus P.H. Kremer ${ }^{2}$, Jacoba M. Spikman² and \\ Rients B. Huitema ${ }^{2}$ \\ ${ }^{1}$ University of Amsterdam, Department of Brain and Cognition, Nieuwe Achtergracht 129B, P.O. Box 15.915, 1001 NK Amsterdam, The Netherlands \\ ${ }^{2}$ University of Groningen, University Medical Center Groningen, Department of Neurology, Hanzeplein 1, P.O. Box 30.001, 9700 RB Groningen, \\ The Netherlands
}

(Received January 27, 2020; Final Revision May 20, 2020; Accepted June 24, 2020; First Published Online August 19, 2020)

\begin{abstract}
Objectives: Neurodegenerative diseases (NDDs), such as Alzheimer's disease, frontotemporal dementia, dementia with Lewy bodies, and Huntington's disease, inevitably lead to impairments in higher-order cognitive functions, including the perception of emotional cues and decision-making behavior. Such impairments are likely to cause risky daily life behavior, for instance, in traffic. Impaired recognition of emotional expressions, such as fear, is considered a marker of impaired experience of emotions. Lower fear experience can, in turn, be related to risk-taking behavior. The aim of our study was to investigate whether impaired emotion recognition in patients with NDD is indeed related to unsafe decision-making in risky everyday life situations, which has not been investigated yet. Methods: Fifty-one patients with an NDD were included. Emotion recognition was measured with the Facial Expressions of Emotions: Stimuli and Test (FEEST). Risk-taking behavior was measured with driving simulator scenarios and the Action Selection Test (AST). Data from matched healthy controls were used: FEEST $(n=182)$, AST $(n=36)$, and driving simulator $(n=18)$.

Results: Compared to healthy controls, patients showed significantly worse emotion recognition, particularly of anger, disgust, fear, and sadness. Furthermore, patients took significantly more risks in the driving simulator rides and the AST. Only poor recognition of fear was related to a higher amount of risky decisions in situations involving a direct danger. Conclusions: To determine whether patients with an NDD are still fit to drive, it is crucial to assess their ability to make safe decisions. Measuring emotion recognition may be a valuable contribution to this judgment.
\end{abstract}

Keywords: Neurodegenerative diseases, Facial emotion recognition, Risky decision-making, Fitness to drive, Emotional processing, Driving simulator

\section{INTRODUCTION}

Neurodegenerative diseases (NDDs) such as Alzheimer's disease (AD) or Huntington's disease (HD) inevitably lead to impairments in brain functions that are crucial for daily life functioning. For instance, is has been shown that a decline in cognitive functions such as memory, attention, and executive function can have severe consequences for the abilities required for critical judgment and adequate decision-making, which are important in risky or hazardous traffic situations (Alameda-Bailén, Salguero-Alcañiz, Merchán-Clavellino, \& Paíno-Quesada, 2017; Cahn-Weiner, Boyle, \& Malloy, 2002).

*Correspondence and reprint requests to: Nils Sven van den Berg, University Medical Center Groningen, Department of Neurology, Unit Neuropsychology HPC AB60, Hanzeplein 1, P.O. Box 30.001, 9700 RB Groningen, The Netherlands. Tel: +316 42137777. E-mail: n.s.vandenberg@uva.nl
Increasingly, research is focusing on deficits in social cognition in various neurodegenerative disorders and their impact on everyday life (Christidi, Migliaccio, SantamaríaGarcía, Santangelo, \& Trojsi, 2018). Social cognition involves the brain functions which allow us to behave adequately in social situations. It is a broad construct comprising different aspects (Adolphs, 2009). These different aspects include the ability to perceive socially important information (such as the perception of emotional facial expressions), the ability to understand intentions and behavior of others (such as creating a theory of mind) and empathic behavior. Neural substrates of social cognition have been found to comprise frontal-subcortical circuits, including the orbitofrontal (Tekin \& Cummings, 2002) and ventromedial prefrontal cortex (Shamay-Tsoory, Tomer, Berger, \& Aharon-Peretz, 2003). Furthermore, medial temporal lobe structures, including the superior temporal sulcus and 
amygdala, have been identified as important brain areas related to social cognition (Carrington \& Bailey, 2009). NDDs often lead to damage to these frontal-subcortical and temporal brain areas, both at a cortical level, such as AD (Tekin \& Cummings, 2002) and frontotemporal dementia (FTD; Rosen et al., 2002), and at a subcortical level, such as HD (Liu, Yang, Burgunder, Cheng, \& Shang, 2016). Accordingly, impairments in social cognition have been found in patients with various NDDs, including $\mathrm{HD}, \mathrm{AD}$, FTD, and Dementia with Lewy Bodies (DLB; Desmarais, Lanctôt, Masellis, Black, \& Herrmann, 2018; Henley et al., 2012; Kumfor et al., 2014).

One of the most important aspects of social cognition is the recognition of emotional facial expressions. It is has been found that the recognition of emotions and the experience of emotions are closely related (Enticott, Johnston, Herring, Hoy, \& Fitzgerald, 2008). Hence, impairments in the ability to recognize facial expressions may be a marker of a decreased ability to experience emotions. A decreased ability to experience emotions can, in turn, interfere with adequate decision-making behavior (Damasio, Tranel, \& Damasio, 1991). In particular, the experience of fear has been found to guide decision behavior in risky situations (Öhman, 2005). Consequently, it seems plausible that impaired recognition of fear, as a probable marker of an impaired experience of fear, is related to increased risky decision behavior. This was indeed found in a study with patients with traumatic brain injury (TBI; Visser-Keizer, Westerhof-Evers, Gerritsen, Van der Naalt, \& Spikman, 2016). TBI is a neurological disorder which often includes damage to the prefrontal brain circuits underlying emotion recognition (Fujiwara, Schwartz, Gao, Black, \& Levine, 2008). Visser-Keizer et al. (2016) found a significant correlation between worse recognition of fearful facial expressions and risky decision-making, using the Iowa Gambling Task (IGT), an experimental task, as a measure of risk-taking behavior (Bechara, Damasio, Damasio, \& Anderson, 1994). In addition, in patients with cerebellar stroke, a relationship between fear-recognition and risktaking behavior in traffic situations was found (van den Berg, Huitema, Spikman, Luijckx, \& de Haan, 2020).

To date, only one study investigated emotion recognition and risky decision-making behavior in patients with an NDD, that is, Parkinson's disease, and indeed found a significant relationship between worse emotion recognition and performance on the IGT (Ibarretxe-Bilbao et al., 2009). However, there is a lack of studies investigating the role of impaired emotion recognition, in particular of fearful expressions, in risk-taking behavior in more natural, everyday life tasks, such as traffic situations, in patients with NDDs. Therefore, the aim of the present study was to assess the role of emotion recognition, in particular of fear, in risky decision-making in traffic-related tasks, in a diverse group of patients with NDDs, including AD, FTD, DLB, and HD, for whom it is well known that those brain circuits that are relevant for emotion perception are or will be affected during the course of the disease (Elamin, Pender, Hardiman, \& Abrahams, 2012). Furthermore, we sought to evaluate under which circumstances this relationship could exist, such as differences between traffic situations with and without a direct danger. Investigating factors related to unsafe decision-making is crucial for a timely and valid assessment of fitness to drive of patients with (early stages of) NDDs.

\section{METHODS}

\section{Design and Setting}

This study was a retrospective review of records, in which data were combined from patients and healthy controls (HCs) who took part in two larger studies investigating AD, FTD, DLB, and Mild Cognitive Impairment (MCI; 'DUAL-Positron Emission Tomography (PET) in Dementia') and HD ('Fitness to Drive in Huntington's Disease'). Both study protocols were approved by the Medical Ethical Committee of the University Medical Center (number 2014.320 and 2015.310, respectively). The patients of the DUAL-PET study were recruited through a collaboration of ten memory clinics (The North Netherlands Memory Research Network). Patients in local centers were referred to the Alzheimer Research Center of the University Medical Center Groningen (UMCG). HD patients were approached by their clinician for inclusion. All participants were seen at the UMCG, Department of Neurology, Unit Neuropsychology.

Furthermore, HCs were included in order to compare the test results between patients and HCs. HCs were volunteers, recruited by advertisements in the Alzheimer Research Center and by online advertisements. They were also tested in the UMCG. HCs performed the same test protocol as the patient group. In addition to this, extra $\mathrm{HC}$ data from previous studies at the Department of Neurology were available for the emotion recognition task and the risk-taking behavior task. These additional HCs had participated in related studies at the Department of Neurology, which involved a neuropsychological assessment of social cognition tests of approximately 1 to $1.5 \mathrm{~h}$.

All patients and HCs who took part in driving-related studies had to have a car driver's license in order to be eligible for inclusion for this study. Participants had to be "active drivers": they should have driven at least $300 \mathrm{~km}$ in the last year. This criterion has also been used in previous studies (e.g., Jacobs et al., 2019). Exclusion criteria for all participants consisted of substance abuse, serious psychiatric, or neurological disorders (other than an NDD in case of patients) or insufficient command of the Dutch language. All participants signed a written informed consent and were treated in accordance with the Declaration of Helsinki.

\section{Participants}

Fifty-one patients diagnosed with an NDD were included. The group of patients was diagnosed according to the current clinical criteria and consisted of 31 patients diagnosed with AD (19 with AD dementia (McKhann et al., 2011) and 
12 with MCI due to AD (Albert et al., 2011)), 4 with FTD (Rascovsky et al., 2011), 7 with DLB (McKeith et al., 2005), and 9 patients with HD (8 with symptomatic HD and 1 with pre-symptomatic HD) (Kieburtz, 1996). Diagnoses of AD, FTD, and DLB were, apart from neuropsychological assessment, confirmed with structural magnetic resonance imaging, cerebrospinal fluid biomarkers, Pittsburgh compound B PET, and 2-[18 F]fluoro-2-deoxy-D-glucose PET. Diagnoses of HD were confirmed by genetic analysis.

\section{Measures}

A neuropsychological assessment was performed to assess emotion recognition and risk-taking behavior. The following tests were performed in this order: The Ekman 60 Faces Test of the Facial Expressions of Emotions - Stimuli and Test (FEEST), The Action Selection Test (AST), and three drives on a driving simulator. Furthermore, a subgroup of patients performed a few additional neuropsychological tests, such as the Trail Making Test, a measure of psychomotor speed (Reitan, 1958). The total testing time took approximately $1-1.5 \mathrm{~h}$.

\section{Emotion recognition}

The Ekman 60 Faces Test of the FEEST (Young, Perrett, Calder, Sprengelmeyer, \& Ekman, 2002) is a sensitive and commonly used measure of emotion recognition (Voncken, Timmerman, Spikman, \& Huitema, 2018). Sixty faces displaying one of the six basic emotions (anger, disgust, fear, happiness, sadness, and surprise) are shown, one at a time. Every emotion expression is presented 10 times for $3 \mathrm{~s}$ in a randomized order, after which six labels are presented and the participant is asked to indicate which emotional expression was shown. The six basic emotion scores (FEEST-Ang, FEEST-Disg, FEEST-Fear, FEEST-Hap, FEEST-Sad, and FEEST-Sur) range from 0 to 10 , and the total score (FEEST-Tot) ranges from 0 to 60 . Higher scores on the FEEST indicate better performance.

\section{The Action Selection Test}

The AST from the SWOV Institute for Road Safety Research (Vlakveld, 2011) was used to measure risk assessment and hazard anticipation in traffic situations, which has also been used by Van den Berg et al. (2020) and by Piersma et al. (2016). Note that this same test has been referred to as the "hazard perception test" by Piersma et al. (2016). In this test, 25 pictures of different traffic situations from a car driver's perspective are presented on a computer screen. The situations contain direct dangers, such as a child running across the street, which have to be directly evaluated and anticipated. Participants are asked to indicate what they would do in that particular situation: do nothing, release accelerator, or brake. Every picture is shown for $8 \mathrm{~s}$, but participants could respond after these $8 \mathrm{~s}$. This long exposure time was deliberately chosen by Vlakveld et al. (2011), as the test was developed with the aim of assessing risk-taking behavior in situations where it would be expected that the hazard was detected. In contrast to real driving behavior, the situation is completely new to the participants in a static picture; the static pictures do not show how situations have developed. Hence, participants may have needed more time to detect the potential hazard in the static pictures of the AST. The responses were rated by experts as very safe, safe, correct, unsafe, or very unsafe (Vlakveld, 2011). We assigned zero points to correct or (very) safe responses, one point to unsafe responses, and two points to very unsafe responses. The outcome measure was the sum score of unsafe and very unsafe responses, where a higher score indicates more risk-taking behavior. This score, termed AST, was used as a measure of risk behavior in situations involving anticipating a direct danger.

\section{Driving simulator tasks}

Two scenarios in an advanced driving simulator were used to measure risky decision-making behavior: (1) the swing drive, a scenario without the presence of direct dangerous situations and (2) the intersections drive, a scenario involving anticipating direct dangerous situations.

The driving simulator used for the current study has also been used in previous studies (e.g., Dotzauer, Caljouw, De Waard, \& Brouwer, 2013; Dotzauer, Caljouw, De Waard, \& Brouwer, 2015; Dotzauer, De Waard, Caljouw, Pöhler, $\&$ Brouwer, 2015). The configuration of the driving simulator consists of a projection screen stage and an open cabin "mock-up" standing within this stage. It contains a custommade force-feedback steering wheel, accelerator, clutch, and brake pedals. The projection screen stage consists of three video projectors and a large flat-screen of 6-meter length, bent 60 degrees inwards at $1 / 3$ and $2 / 3$ of its length, which presents the driver with a wide horizontal view. The software used in the simulator was from St Software. Both drives require driving on a winding two-lane country road with alternating left-right curves of 40 degrees and 500-meter radius, while there is a continuous stream of traffic from the opposing direction, but no traffic on the lane of the simulator drives. The car was set to automatic transmission.

Prior to the swing drive and the intersections drive, participants performed an exercise drive, the fixed drive, to get used to the simulator. In the fixed drive, which takes approximately $5 \mathrm{~min}$, participants are instructed to drive safely in the middle of their lane. The speed of the car is automatically regulated ("fixed") in this drive, so participants only have to steer during this drive, to get used to simulator environment and the steering wheel. In particular, they will be able to experience the sensitivity of the steering wheel in order to know how to stay in the middle of their lane. The steering wheel vibrates when participants get off the road. The speed is gradually increased during this drive, so that participants can get a sense of how fast a particular speed would feel like. The speed starts at 50 kilometers per $\mathrm{hr}(\mathrm{km} / \mathrm{hr})$ and increases in steps of $10 \mathrm{~km} / \mathrm{hr}$ until $100 \mathrm{~km} / \mathrm{hr}$. 
In the swing drive, which takes approximately $5 \mathrm{~min}$, participants are instructed to drive safely in the middle of their lane. Halfway through the drive, participants are instructed to drive at a speed as if they were in a hurry, but that their driving should still remain safely. Hence, there was no specific speed limit in this second half of the drive. The outcome measure of this ride is the Standard Deviation of the Lateral Position, termed Swing-SDLP, that is, the lateral swaying of the car, in the second half of this drive. The Swing-SDLP generally increases as driving speed increases (Dijksterhuis, de Waard, Brookhuis, Mulder, \& de Jong, 2013). Therefore, in the Swing drive, the Swing-SDLP is related to the amount of risk participants take, because participants are instructed to drive at a speed that is still safe; they need to adjust their driving behavior in order to avoid a risky situation. For instance, they can reduce their speed if they feel that they are losing control. When vehicle control decreases, SDLP increases (Verster \& Roth, 2011). The speed at which participants feel comfortable and feel having control, differs from one to another (Dijksterhuis et al., 2013). Therefore, driving speed alone would probably be a less accurate measure. A higher Swing-SDLP score indicates increased risk-taking behavior. The Swing-SDLP measures risk-taking behavior without the presence of a direct dangerous situation; a risky situation could be caused by the patients' behavior.

In the intersections drive, which takes approximately $10 \mathrm{~min}$, participants have to negotiate intersections with varying priority regulations. Participants have to obey the rules, including the speed limits and priority rules. Apart from oncoming traffic on the opposing direction, there is also traffic coming from the right and left at the intersections. At three intersections, participants have to give way. These intersections involve an uncontrolled intersection, a yield-signed intersection, and an intersection with traffic lights. There are two blocks with a maximum speed of $60 \mathrm{~km} / \mathrm{h}$ and two blocks with a maximum speed of $80 \mathrm{~km} / \mathrm{h}$. Participants got one point for each time they did not stop at an intersection and for each speeding violation, based on their average speed per block. Lastly, patients got one point in case of a collision during this ride. The outcome measure, termed Inters-Viol, was the sum score of violations where a higher score indicates more risk-taking behavior. The Inters-Viol measures risktaking behavior in situations involving anticipating a direct danger, such as a car crossing an intersection.

\section{Statistical Analyses}

To test for differences between patients and HCs, $t$-tests for independent samples for parametric data and Mann-Whitney U (MWU)-tests and Kruskal-Wallis H-tests for non-parametric data were performed. Effect sizes were calculated for the comparisons between patients and HCs (Hedge's $g$ ). Pearson's correlations were performed to examine the relationship between age and all test variables. To examine the relationship between emotion recognition and risk-taking behavior, partial correlation analyses with age as covariate, between all FEEST scores on the one hand and the AST,
Swing-SDLP, and Inters-Viol on the other hand were performed. Missing values in the AST were replaced by the series mean of the corresponding test item. The overall alpha level was set at .05, two-sided. All statistical analyses were performed with IBM SPSS statistics 23 (Armonk, NY, USA).

\section{RESULTS}

\section{Missing Values}

Regarding the AST, for one patient, three out of 25 items were missing. For one HC, one of the 25 items was missing. Since this concerned $<15 \%$ missing, these missing values were replaced by the series mean of the corresponding test item within the respective group (patients or $\mathrm{HCs}$ ).

Furthermore, eight patients were not able to complete the rides in the driving simulator, due to symptoms of simulator sickness ( $n=5$, of which three $\mathrm{AD}$, one FTD, and one HD), excessive fatigue ( $n=2$, of which one FTD and one AD), or inability to comprehend the device instructions ( $n=1$, DLB). Therefore, Swing-SDLP is based on data from the remaining 43 patients. For Inters-Viol, data are missing for an additional three patients because of simulator sickness $(n=2$, both AD) and excessive fatigue ( $n=1$, DLB), which was not yet present in the Swing drive. Therefore, Inters-Viol is based on the remaining 40 participants. An MWU-analysis showed that patients who were not able to complete the driving simulator drives had significantly lower FEEST-Tot scores in comparison to patients who were able to complete the simulator drives $(M W U Z=-2.55, p<.05)$.

\section{Participants}

Descriptive statistics of the three HC groups (HCs who performed the FEEST, HCs who performed the AST, and HCs who performed the driving simulator rides) and the patient group and the patient subgroups are presented in Table 1. There were no significant differences between patients and HCs who performed the FEEST with respect to age $(t=-0.15, p=.884)$, educational level $(t=1.10$, $p=.271)$, or $\operatorname{sex}\left(\chi^{2}=2.77, p=.096\right)$. Furthermore, there were no significant differences between patients and HCs who performed the driving simulator rides with respect to age $(M W U Z=-1.75, p=.080)$, educational level $(M W U$ $Z=-1.23, p=.219)$, and $\operatorname{sex}\left(\chi^{2}=.38, p=.538\right)$. In addition, there were no significant differences between patients and HCs who performed the AST with respect to sex $\left(\chi^{2}=1.40, p=.236\right)$. However, HCs who performed the AST were significantly younger ( $M W U \quad Z=-2.37$, $p=.018)$ and had a significantly higher educational level ( $M W U Z=-3.46, p=.001)$. Therefore, age and educational level were entered as covariates for the comparisons between patients and HCs for the AST.

Table 2 shows that there are no significant differences between the patient subgroups on any of the measures. In addition, the Mini-Mental State Examination (MMSE) score 
Table 1. Descriptive statistics of the three HC groups, the total patient group, and the subgroups of patients

\begin{tabular}{|c|c|c|c|c|c|c|c|c|}
\hline & $\begin{array}{c}\text { HC-FEEST } \\
(n=182)\end{array}$ & $\begin{array}{c}\text { HC-AST } \\
(n=36)\end{array}$ & $\begin{array}{l}\text { HC-Driv. } \\
\text { simulator } \\
(n=18)\end{array}$ & $\begin{array}{l}\text { All patients } \\
(n=51)\end{array}$ & $\underset{(n=31)}{\mathrm{AD}}$ & $\begin{array}{l}\text { FTD } \\
(n=4)\end{array}$ & $\begin{array}{l}\text { DLB } \\
(n=7)\end{array}$ & $\begin{array}{c}\mathrm{HD} \\
(n=9)\end{array}$ \\
\hline Age, $M(\mathrm{SD})$ & $64.3(5.4)$ & $51.8(20.5)$ & $67.9(5.2)$ & $64.5(8.4)$ & $65.9(6.8)$ & $69.0(7.0)$ & $68.0(6.1)$ & $54.9(9.5)$ \\
\hline Sex, men $(\%)$ & $105(57.7 \%)$ & $21(58.3 \%)$ & $12(66.7 \%)$ & $36(70.6 \%)$ & $20(64.5 \%)$ & $3(75.0 \%)$ & $6(85.7 \%)$ & $7(77.8 \%)$ \\
\hline Education, $M$ (SD) & $5.1(1.0)$ & $5.8(0.8)$ & $5.4(0.9)$ & $4.8(1.3)$ & $5.1(1.3)$ & $4.3(2.1)$ & $3.9(1.1)$ & $5.1(.78)$ \\
\hline
\end{tabular}

Note. Education =7-point scale ranging from 1 (low education) to 7 (university education); HC-FEEST = healthy controls who performed the Ekman 60-faces test of the Facial Expressions of Emotions: Stimuli and Test; HC-AST = healthy controls who performed the Action Selection Test; HC - Driv. Simulator $=$ healthy controls who performed the driving simulator rides.

Table 2. Performance on the FEEST and the AST for all subgroups of patients as well as comparisons between all patient subgroups (Kruskall-Wallis $H$-tests)

\begin{tabular}{|c|c|c|c|c|c|c|}
\hline \multirow[b]{2}{*}{ Measure } & \multirow{2}{*}{$\begin{array}{c}\mathrm{AD} \\
n=31 \\
M(\mathrm{SD})\end{array}$} & \multirow{2}{*}{$\begin{array}{c}\text { FTD } \\
n=4\end{array}$} & \multirow{2}{*}{$\begin{array}{c}\text { DLB } \\
n=7\end{array}$} & \multirow{2}{*}{$\begin{array}{c}\mathrm{HD} \\
n=9\end{array}$} & \multicolumn{2}{|c|}{$\begin{array}{c}\text { Difference } \\
\text { AD-FTD-DLB-HD }\end{array}$} \\
\hline & & & & & $H$ & $p$ \\
\hline FEEST-Ang & $7.1(2.7)$ & $6.0(2.2)$ & $6.4(2.0)$ & $5.6(3.1)$ & 3.34 & .342 \\
\hline FEEST-Disg & $6.0(2.5)$ & $4.8(3.3)$ & $5.9(2.3)$ & $4.9(2.9)$ & 1.56 & .670 \\
\hline FEEST-Fear & $4.7(2.2)$ & $3.3(2.1)$ & $3.7(2.1)$ & $3.2(2.6)$ & 3.41 & .332 \\
\hline FEEST-Hap & $9.7(0.8)$ & $9.3(1.0)$ & $9.4(1.5)$ & $10.0(0.0)$ & 4.63 & .201 \\
\hline FEEST-Sad & $5.1(2.2)$ & $5.8(2.5)$ & $4.3(3.3)$ & $4.9(3.4)$ & 0.90 & .825 \\
\hline FEEST-Sur & $8.8(1.5)$ & $6.5(3.7)$ & 7.9 (1.9) & $8.2(1.3)$ & 6.05 & .109 \\
\hline FEEST-Tot, & $41.3(7.8)$ & $35.5(12.0)$ & $37.6(9.3)$ & $36.8(10.6)$ & 2.24 & .525 \\
\hline Range & $27-58$ & $19-47$ & $20-46$ & $24-54$ & & \\
\hline AST & $7.1(4.4)$ & $6.3(6.0)$ & $7.3(2.2)$ & $6.9(5.5)$ & 0.72 & .868 \\
\hline Swing-SDLP & $30.6(7.9)$ & $33.2(0.9)$ & $36.6(4.0)$ & $33.5(9.8)$ & 5.50 & .138 \\
\hline Inters-Viol & $1.5(1.4)$ & $2.0(1.4)$ & $3.0(1.9)$ & $0.5(0.5)$ & 7.17 & .067 \\
\hline
\end{tabular}

*Chi-value of the chi-square test.

Note . Inters-Viol = risk-taking behavior score of the intersections drive.

was available for all AD, FTD, and DLB patients and for five HD patients (total $n$ of MMSE scores: 47). A Kruskall-Wallis $H$-test across all patient subgroups showed that the different subgroups did not statistically differ regarding their MMSE score $(H=6.28, p=.099)$, indicating that they did not differ regarding their cognitive disease severity.

Within the patient group, a higher age was significantly associated with a worse perception of anger, that is, a lower FEEST-Ang $(r=-.30, p<.05)$, and with increased risk-taking behavior in the Intersections drive, that is, a higher IntersViol $(r=.39, p<.05)$. There were no significant correlations between age and FEEST-Disg $(r=-.07, p=.633)$, FEESTFear $(r=-.04, p=.784)$, FEEST-Hap $(r=-.25$, $p=.075)$, FEEST-Sad $(r=-.14, p=.333)$, FEEST-Sur $(r=-.10, p=.487)$, FEEST-Tot $(r=-.21, p=.148)$, $\operatorname{AST}(r=.12, p=.419)$, and Swing-SDLP $(r=.28, p=.067)$.

\section{Emotion Recognition and Risk-Taking Behavior}

Table 3 shows that all FEEST scores were significantly lower in patients in comparison to HCs, except for FEEST-Hap and FEEST-Sur. AST and Inters-Viol were significantly higher in the patient group when compared to HCs, that is, patients showed significantly more risk-taking behavior than $\mathrm{HCs}$ in the AST and the Intersections drive. There were no significant differences between patients and HCs regarding Swing-SDLP in the second half of the swing drive. However, patients drove significantly slower than HCs in the second half of the swing drive (Swing-Speed). The effect sizes (Hedges' $g$ ) of the significant differences between patients and HCs were moderate to large.

\section{Associations Between Emotion Recognition and Risk-Taking Behavior in the Patient Group}

Partial correlations, with age as covariate, between the FEEST and the risk-behavior variables were performed. As can be seen in Table 4, significant correlations were only found for either FEEST-total or FEEST-Fear scores: between FEEST-Tot and AST, between FEEST-Fear and AST and between FEEST-Fear and Inters-Viol. These significant negative correlations indicate that worse performance on the respective FEEST scores was related to increased risk-taking behavior in the AST or Inters-Viol. There were no significant relations between any of the FEEST scores and Swing-SDLP. We found no indications for processing speed to have 
Table 3. Performance on the FEEST, the AST, and the driving simulator (means and SDs) and comparisons between HCs and patients (MWUtests or ANCOVA for the AST, with age and educational level added as covariates)

\begin{tabular}{|c|c|c|c|c|c|}
\hline \multirow[b]{2}{*}{ Measure } & \multirow{2}{*}{$\begin{array}{c}\mathrm{HC} \\
M(S D) \\
n=182\end{array}$} & \multirow{2}{*}{$\begin{array}{c}\text { Patients } \\
M(S D) \\
n=51\end{array}$} & \multirow[b]{2}{*}{$Z$} & \multirow[b]{2}{*}{$p$} & \multirow[b]{2}{*}{ Hedges' $g$} \\
\hline & & & & & \\
\hline FEEST-Ang & $7.7(2.0)$ & $6.7(2.6)$ & -2.37 & $<.05$ & 0.5 \\
\hline FEEST-Disg & $7.7(2.1)$ & $5.7(2.6)$ & -4.95 & $<.001$ & 0.9 \\
\hline FEEST-Fear & $5.6(2.5)$ & $4.2(2.3)$ & -3.78 & $<.001$ & 0.6 \\
\hline FEEST-Hap & $9.8(0.5)$ & $9.7(0.9)$ & -0.42 & .675 & 0.2 \\
\hline FEEST-Sad & 6.7 (1.9) & $5.0(2.5)$ & -4.30 & $<.001$ & 0.8 \\
\hline FEEST-Sur & $8.9(1.3)$ & $8.4(1.8)$ & -1.58 & .114 & 0.4 \\
\hline FEEST-Tot & $46.4(6.0)$ & $39.5(8.9)$ & -5.28 & $<.001$ & 1.0 \\
\hline Range & $23-58$ & $19-58$ & & & \\
\hline \multirow[t]{2}{*}{ AST } & $n=36$ & $n=51$ & $8.81 *$ & $<.01$ & 0.8 \\
\hline & $3.7(3.3)$ & $7.0(4.4)$ & & & \\
\hline \multirow[t]{2}{*}{ Swing-SDLP } & $n=18$ & $n=43$ & & & \\
\hline & $34.5(9.1)$ & $34.1(16.9)$ & -0.77 & .443 & 0.1 \\
\hline Swing-Speed & $100.2(9.0)$ & $89.8(15.1)$ & -2.81 & $<.01$ & 0.8 \\
\hline Inters-Viol & $0.6(1.3)$ & $1.5(1.5)$ & -2.73 & $<.01$ & 0.6 \\
\hline
\end{tabular}

* $F$-value of the ANCOVA instead of the MWU-Z values for the other analyses.

Note. Higher FEEST scores indicate better performance, while a higher AST, Swing-SDLP or Inters-Viol indicate worse performance; ANCOVA = analysis of covariance; Swing-Speed $=$ speed $($ in $\mathrm{km} / \mathrm{h}$ ) in the swing drive; Inters-Viol = risk-taking behavior score of the intersections drive.

Table 4. Partial correlations in the patient group between the FEEST scores and the AST, Swing-SDLP and inters-viol, with age as covariate

\begin{tabular}{llcc}
\hline \hline & $\begin{array}{c}\text { AST } \\
(n=51)\end{array}$ & $\begin{array}{c}\text { Swing-SDLP } \\
(n=43)\end{array}$ & $\begin{array}{c}\text { Inters-Viol } \\
(n=40)\end{array}$ \\
\hline FEEST-Ang & -.22 & -.12 & -.24 \\
FEEST-Disg & -.08 & .20 & .09 \\
FEEST-Fear & $-.30 *$ & .00 & $-.32^{*}$ \\
FEEST-Hap & -.06 & .19 & -.29 \\
FEEST-Sad & -.27 & -.05 & .06 \\
FEEST-Sur & -.22 & .05 & -.30 \\
FEEST-Tot & $-.29 *$ & -.11 & -.20 \\
\hline \hline
\end{tabular}

Note. Inters-Viol $=$ risk-taking behavior score of the intersections drive. $* p<.05$.

reduced the scores in the driving simulator, as the time to complete part A of the Trail Making Test was not significantly associated with the Swing-SDLP $(r=.01, p=.954)$ and Inters-Viol $(r=.24, p=.141)$.

\section{DISCUSSION}

The main aim of the present study was to investigate whether a neuropsychological test of emotion recognition, an important aspect of social cognition, might be useful to indicate unsafe decision-making behavior in traffic-related situations in a heterogeneous group of patients with NDDs, among which $\mathrm{AD}$, FTD, DLB, and HD. In comparison to HCs, patients took significantly more risks in the AST and in a driving simulator drive. They also performed significantly worse with respect to the overall recognition of facial emotional expressions, and in particular of anger, disgust, fear, and sadness. Moreover, we found that impaired overall recognition of emotional expressions was significantly associated with increased risk-taking behavior in situations involving anticipating a direct danger. Amongst the different basic emotional expressions, only the ability to recognize fearful expressions was found as an indicator of risky decision behavior, which was in line with our expectations. This finding supports the hypothesis that deficits in emotion recognition, an important aspect of social cognition, might be markers of unsafe decision-making behavior in hazardous, traffic-related situations in patients with NDD.

The association between the recognition of particularly fearful facial emotions and risk-taking behavior is thought to be mediated by the underlying ability to experience emotions. According to a prominent theory, the bodily feedback hypothesis, the concepts of facial expression of emotions, experience of emotions, and recognition of emotions are closely related (Price \& Harmon-Jones, 2015). It has been found that experimentally manipulating someone's emotional expression can influence the experience of that particular emotion (Laird, 1974). Furthermore, experimentally blocking someone's imitation of the facial emotional expression of another individual has been found to interfere with the correct identification of that specific emotion (Niedenthal, Brauer, Halberstadt, \& Innes-Ker, 2001; Oberman, Winkielman, \& Ramachandran, 2007). According to a related theory, the somatic marker hypothesis, the experience of emotions plays, in turn, an important role in decision-making (Damasio et al., 1991). Each emotion has a specific motivational goal and contributes in a distinctive way to behavior (Zeelenberg, Nelissen, Breugelmans, \& Pieters, 2008). In risky situations, the experience of fear is 
most likely to guide decisions that might have dangerous consequences (Steigenberger, 2015). Fearful emotions can be processed quickly, enabling instantaneous responses in order to avoid a risky outcome (Hung et al., 2010). Consequently, it seems likely that in the present study patients with a decreased ability to recognize fearful facial expressions, as a probable marker of impaired experience of fear, could not be guided by a fearful experience to prevent them from making risky decisions in the AST and the intersections drive. The finding that only the recognition of fearful expressions, and none of the other basic emotional expressions, was related to risk-taking behavior, suggests that this relationship could not be attributed to an overall decrease in cognition. This idea that emotion recognition is a separate construct is furthermore supported by findings of Spikman et al. (2012), who found that deficits in emotion recognition in patients with TBI were not attributable to deficits in other cognitive functions, such as attention, mental speed, memory, and executive functioning. In addition, our secondary analyses showed that performance on the driving simulator was not confounded by deficits in psychomotor speed. Lastly, the relationship between emotion recognition and risk-taking behavior was controlled for the influence of age.

The significant association between fear recognition and risk-taking behavior was only found in tasks with situations involving direct danger, which was the case in the AST and the intersections drive. In these tasks, various contextual aspects, such as cars or pedestrians suddenly crossing the street, had to be evaluated and anticipated. During this evaluation, patients had to decide what was most appropriate to do in order to avoid a potential dreadful outcome, such as a collision. In the swing drive, on the other hand, patients had to adjust their driving speed in order to decrease the amount of swaying of the car. Not compensating for excessive swaying could have led to serious risky and harmful situations. However, in contrast to the AST and the intersections drive, the contextual aspects of the swing drive did not involve immediate danger. Hence, it seems that the ability to recognize and experience fearful emotions is especially important in guiding decision behavior when the contextual aspects contain direct dangers with potential negative outcomes. These direct dangers probably provoke a fearful emotion, which could in turn guide decision behavior (SchmidtDaffy, 2013).

The present study included patients with progressive neurological disorders of which it is known that brain networks important for social cognition are likely to be affected in the course of the disease (Elamin et al., 2012). Previous studies have also included patients with different etiologies on the basis of neuropsychological profiles (Chen et al., 2018; Goodkind et al., 2012), which can be methodologically justified (Cipolotti et al., 2015). Moreover, separating groups based on a diagnosis of an NDD can be arbitrary, because there can be a large phenotypic heterogeneity within a diagnostic group and a large overlap in symptoms between diagnostic groups (Ryan, Fransquet, Wrigglesworth, \& Lacaze, 2018). Indeed, we found no significant differences between the patient subgroups regarding their overall cognition, as assessed with the MMSE, a screening instrument for dementia (Lacy, Kaemmerer, \& Czipri, 2015). In addition, we found that the patient subgroups did not differ regarding their performance on the FEEST, AST, or driving simulator drives.

This study is subject to some limitations. First, several patients in the present study were unable to complete the driving simulator rides (this could not be attributed to a specific disease subgroup), because of simulator sickness or decreased mental endurance, which could have skewed these findings. However, the finding that patients who were not able to complete the driving simulator rides were significantly worse in recognizing emotions than patients who completed the rides, indicates that the current relationships are probably underestimates; based on our findings, those patients with worse emotion recognition abilities would be expected to perform worse in the driving simulator. Classen et al. (2011) described that simulator sickness is a common problem in especially older people. Fortunately, because of the upcoming technical improvements, including higher refresh rates and better simulator configuration and calibration, simulator sickness is becoming less frequent. Second, the number of HCs who performed the AST and the driving simulator rides was relatively small. However, the main aim of this study was to assess the associations between emotion recognition and risk-taking behavior within the patient group. Lastly, the size of the subgroups of patients was too small to analyze them separately. Consequently, we cannot draw conclusions about differences between the individual etiology subgroups. However, this study was not set up to allow us to examine this issue directly. Moreover, as described earlier, we found no indications for differences in disease severity or differences in test performance between the patient subgroups.

In conclusion, the results of this study show that, irrespective of exact NDD etiology, impaired emotion recognition could be an indicator of daily life risk-taking behavior. This study extends previous studies, which have shown that an impaired emotion recognition can be an indicator of a reduced quality of life and an indicator of the development of behavioral disturbances or mood disorders (Henry, Von Hippel, Molenberghs, Lee, \& Sachdev, 2016; Phillips, Scott, Henry, Mowat, \& Bell, 2010). Risk-taking behavior has been found to be an important aspect of the fitness to drive in patients with an NDD (Piersma et al., 2016). Therefore, in order to determine whether patients with (early stages of) an NDD are still fit to drive, it is imperative to assess their ability to make safe decisions. However, the assessment of risktaking behavior directly with the AST or driving simulator rides is hampered by the fact that the availability of these tasks is limited; the AST is not publicly available, because it includes pictures of the theory exam for the Dutch driving license and driving simulators can only be found in few diagnostic settings. Moreover, as described earlier, it took patients time to familiarize with the driving simulator setup. The FEEST does not have these restrictions and can be easily 
assessed in patients with an NDD. Hence, we suggest that assessing emotion recognition may be a valuable supplement in the assessment of fitness to drive in patients with an NDD. This can be helpful, because finding contributing factors to the fitness to drive in these patients is still a topic of ongoing debate (Jacobs, Hart, \& Roos, 2017). Future studies are needed to extend these results by looking at the role of facial emotion recognition in risk-taking behavior in on-road driving behavior and to investigate this relationship in the separate NDD patient groups.

\section{ACKNOWLEDGMENTS}

This study was supported by a European Research Council Advanced Grant (\#339374) to E. H. F. de Haan.

\section{CONFLICT OF INTEREST}

The authors have nothing to disclose.

\section{REFERENCES}

Adolphs, R. (2009). The social brain: neural basis of social knowledge. Annual Review of Psychology, 60, 693-716. https://doi.org/ 10.1146/annurev.psych.60.110707.163514

Alameda-Bailén, J.R., Salguero-Alcañiz, M.P., Merchán-Clavellino, A., \& Paíno-Quesada, S. (2017). Cognitive mechanisms in decision-making in patients with mild Alzheimer disease. Current Alzheimer Research, 14. https://doi.org/10.2174/ 1567205014666170417113834

Albert, M.S., DeKosky, S.T., Dickson, D., Dubois, B., Feldman, H.H., Fox, N.C., ... Phelps, C.H. (2011). The diagnosis of mild cognitive impairment due to Alzheimer's disease: recommendations from the National Institute on Aging-Alzheimer's Association workgroups on diagnostic guidelines for Alzheimer's disease. Alzheimer's and Dementia, 7(3), 270-279. https://doi.org/10. 1016/j.jalz.2011.03.008

Bechara, A., Damasio, A.R., Damasio, H., \& Anderson, S.W. (1994). Insensitivity to future consequences following damage to human prefrontal cortex. Cognition. Cognition, 50(1-3), 7-15. https:// doi.org/10.1016/0010-0277(94)90018-3

Cahn-Weiner, D.A., Boyle, P.A., \& Malloy, P.F. (2002). Tests of executive function predict instrumental activities of daily living in community-dwelling older individuals. Applied Neuropsychology, 9(3), 187-191. https://doi.org/10.1207/S15324826AN0903_8

Carrington, S.J., \& Bailey, A.J. (2009). Are there theory of mind regions in the brain? A review of the neuroimaging literature. Human Brain Mapping, 30(8), 2313-2335. https://doi.org/10. 1002/hbm.20671

Chen, K.H., Wells, J.L., Otero, M.C., Lwi, S.J., Haase, C.M., \& Levenson, R.W. (2018). Greater experience of negative non-target emotions by patients with neurodegenerative diseases is related to lower emotional well-being in caregivers. Dementia and Geriatric Cognitive Disorders, 44(5-6), 245-255. https:// doi.org/10.1159/000481132

Christidi, F., Migliaccio, R., Santamaría-García, H., Santangelo, G., \& Trojsi, F. (2018). Social cognition dysfunctions in neurodegenerative diseases: neuroanatomical correlates and clinical implications.
Behavioural Neurology, 2018. https://doi.org/10.1155/2018/ 1849794

Cipolotti, L., Healy, C., Chan, E., Bolsover, F., Lecce, F., White, M., ... Bozzali, M. (2015). The impact of different aetiologies on the cognitive performance of frontal patients. Neuropsychologia, 68, 21-30. https://doi.org/10.1016/j.neuropsychologia.2014.12.025

Classen, S., Bewernitz, M., \& Shechtman, O. (2011). driving simulator sickness: an evidence-based review of the literature. American Journal of Occupational Therapy, 65(2), 179-188. https://doi.org/10.5014/ajot.2011.000802

Damasio, A.R., Tranel, D., \& Damasio, H.C. (1991). Somatic markers and the guidance of behavior: Theory and preliminary testing. In Frontal Lobe Function and Dysfunction (pp. 217-229). New York: Oxford University Press.

Desmarais, P., Lanctôt, K.L., Masellis, M., Black, S.E., \& Herrmann, N. (2018). Social inappropriateness in neurodegenerative disorders. International Psychogeriatrics, 30(2), 197-207. https://doi.org/10.1017/S1041610217001260

Dijksterhuis, C., de Waard, D., Brookhuis, K.A., Mulder, B.L.J.M., \& de Jong, R. (2013). Classifying visuomotor workload in a driving simulator using subject specific spatial brain patterns. Frontiers in Neuroscience, 7(149). https://doi.org/10.3389/ fnins.2013.00149

Dotzauer, M., Caljouw, S.R., De Waard, D., \& Brouwer, W.H. (2013). Intersection assistance: a safe solution for older drivers? Accident Analysis and Prevention, 59, 522-528. https://doi.org/ 10.1016/j.aap.2013.07.024

Dotzauer, M., Caljouw, S.R., De Waard, D., \& Brouwer, W.H. (2015). Longer-term effects of ADAS use on speed and headway control in drivers diagnosed with Parkinson's disease. Traffic Injury Prevention, 16(1), 10-16. https://doi.org/10.1080/ 15389588.2014.909037

Dotzauer, M., De Waard, D., Caljouw, S.R., Pöhler, G., \& Brouwer, W.H. (2015). Behavioral adaptation of young and older drivers to an intersection crossing advisory system. Accident Analysis and Prevention, 74, 24-32. https://doi.org/10.1016/j.aap.2014.09.030

Elamin, M., Pender, N., Hardiman, O., \& Abrahams, S. (2012). Social cognition in neurodegenerative disorders: A systematic review. Journal of Neurology, Neurosurgery and Psychiatry, 83(11), 1071-1079. https://doi.org/10.1136/jnnp-2012-302817

Enticott, P.G., Johnston, P.J., Herring, S.E., Hoy, K.E., \& Fitzgerald, P.B. (2008). Mirror neuron activation is associated with facial emotion processing. Neuropsychologia, 46(11), 2851-2854. https://doi.org/10.1016/j.neuropsychologia.2008. 04.022

Fujiwara, E., Schwartz, M.L., Gao, F., Black, S.E., \& Levine, B. (2008). Ventral frontal cortex functions and quantified MRI in traumatic brain injury. Neuropsychologia, 46(2), 461-474. https://doi.org/10.1016/j.neuropsychologia.2007.08.027

Goodkind, M.S., Sollberger, M., Gyurak, A., Rosen, H.J., Rankin, K.P., Miller, B., \& Levenson, R. (2012). Tracking emotional valence: the role of the orbitofrontal cortex. Human Brain Mapping, 33(4), 753-762. https://doi.org/10.1002/hbm.21251

Henley, S.M.D., Novak, M.J.U., Frost, C., King, J., Tabrizi, S.J., \& Warren, J.D. (2012). Emotion recognition in Huntington's disease: a systematic review. Neuroscience and Biobehavioral Reviews. https://doi.org/10.1016/j.neubiorev.2011.06.002

Henry, J.D., Von Hippel, W., Molenberghs, P., Lee, T., \& Sachdev, P.S. (2016). Clinical assessment of social cognitive function in neurological disorders. Nature Reviews Neurology, 12(1), 28-39. https://doi.org/10.1038/nrneurol.2015.229 
Hung, Y., Smith, M.L., Bayle, D.J., Mills, T., Cheyne, D., \& Taylor, M.J. (2010). Unattended emotional faces elicit early lateralized amygdala-frontal and fusiform activations. NeuroImage, 50(2), 727-733. https://doi.org/10.1016/j.neuroimage.2009.12.093

Ibarretxe-Bilbao, N., Junque, C., Tolosa, E., Marti, M.-J., Valldeoriola, F., Bargallo, N., \& Zarei, M. (2009). Neuroanatomical correlates of impaired decision-making and facial emotion recognition in early Parkinson's disease. The European Journal of Neuroscience, 30(6), 1162-1171. https://doi.org/10. 1111/j.1460-9568.2009.06892.x

Jacobs, M., Hart, E.P., Mejia Miranda, Y., Groeneveld, G.J., van Gerven, J.M.A., \& Roos, R.A.C. (2019). Predictors of simulated driving performance in Huntington's disease. Parkinsonism and Related Disorders, 60, 64-69. https://doi.org/10.1016/j. parkreldis.2018.10.002

Jacobs, M., Hart, E.P., \& Roos, R.A.C. (2017). Driving with a neurodegenerative disorder: an overview of the current literature. Journal of Neurology, 264(8), 1678-1696. https://doi.org/10. 1007/s00415-017-8489-9

Kieburtz, K. (1996). Unified Huntington's disease rating scale: reliability and consistency. Movement Disorders, 11(2), 136-142. https://doi.org/10.1002/mds.870110204

Kumfor, F., Irish, M., Leyton, C., Miller, L., Lah, S., Devenney, E., ... Piguet, O. (2014). Tracking the progression of social cognition in neurodegenerative disorders. Journal of Neurology, Neurosurgery and Psychiatry, 85(10), 1076-1083. https://doi. org/10.1136/jnnp-2013-307098

Lacy, M., Kaemmerer, T., \& Czipri, S. (2015). Standardized mini-mental state examination scores and verbal memory performance at a memory center: implications for cognitive screening. American Journal of Alzheimer's Disease and Other Dementias, 30(2), 145-152. https://doi.org/10.1177/1533317 514539378

Laird, J.D. (1974). Self-attribution of emotion: the effects of expressive behavior on the quality of emotional experience. Journal of Personality and Social Psychology, 29(4), 475-486. https://doi. org/10.1037/h0036125

Liu, W., Yang, J., Burgunder, J.M., Cheng, B., \& Shang, H. (2016). Diffusion imaging studies of Huntington's disease: a meta-analysis. Parkinsonism and Related Disorders, 32, 94-101. https://doi. org/10.1016/j.parkreldis.2016.09.005

McKeith, I.G., Dickson, D.W., Lowe, J., Emre, M., O'Brien, J.T., Feldman, H., ... Consortium on DLB. (2005). Diagnosis and management of dementia with Lewy bodies: third report of the DLB consortium. Neurology, 65(12), 1863-1872. https://doi. org/10.1212/01.wnl.0000187889.17253.b1

McKhann, G.M., Knopman, D.S., Chertkow, H., Hyman, B.T., Jack, C.R., Kawas, C.H., . . Phelps, C.H. (2011). The diagnosis of dementia due to Alzheimer's disease: Recommendations from the National Institute on Aging-Alzheimer's Association workgroups on diagnostic guidelines for Alzheimer's disease. Alzheimer's \& Dementia, 7(3), 263-269. https://doi.org/10. 1016/J.JALZ.2011.03.005

Niedenthal, P.M., Brauer, M., Halberstadt, J.B., \& Innes-Ker, Å.H. (2001). When did her smile drop? Facial mimicry and the influences of emotional state on the detection of change in emotional expression. Cognition and Emotion, 15(6), 853-864. https://doi.org/10.1080/02699930143000194

Oberman, L.M., Winkielman, P., \& Ramachandran, V.S. (2007). Face to face: blocking facial mimicry can selectively impair recognition of emotional expressions. Social Neuroscience, 2(3-4), 167-178. https://doi.org/10.1080/17470910701391943

Öhman, A. (2005). The role of the amygdala in human fear: automatic detection of threat. Psychoneuroendocrinology, 30(10), 953-958. https://doi.org/10.1016/j.psyneuen.2005.03.019

Phillips, L.H., Scott, C., Henry, J.D., Mowat, D., \& Bell, J.S. (2010). Emotion perception in Alzheimer's disease and mood disorder in old age. Psychology and Aging, 25(1), 38-47. https://doi.org/10. 1037/a0017369

Piersma, D., Fuermaier, A.B.M., de Waard, D., Davidse, R.J., de Groot, J., Doumen, M.J.A., ... Tucha, O. (2016). Prediction of fitness to drive in patients with Alzheimer's dementia. PloS One, 11(2), e0149566. https://doi.org/10.1371/journal.pone. 0149566

Price, T.F., \& Harmon-Jones, E. (2015). Embodied emotion: the influence of manipulated facial and bodily states on emotive responses. Wiley Interdisciplinary Reviews: Cognitive Science, 6(6), 461-473. https://doi.org/10.1002/wcs.1370

Rascovsky, K., Hodges, J.R., Knopman, D., Mendez, M.F., Kramer, J.H., Neuhaus, J., ... Miller, B.L. (2011). Sensitivity of revised diagnostic criteria for the behavioural variant of frontotemporal dementia. Brain, 134(9), 2456-2477. https://doi.org/10.1093/ brain/awr179

Reitan, R.M. (1958). Validity of the trail making test as an indicator of organic brain damage. Perceptual and Motor Skills, 8(7), 271-276. https://doi.org/10.2466/PMS.8.7.271-276

Rosen, H.J., Gorno-Tempini, M.L., Goldman, W.P., Perry, R.J., Schuff, N., Weiner, M., ... Miller, B.L. (2002). Patterns of brain atrophy in frontotemporal dementia and semantic dementia. Neurology, 58(2), 198-208. https://doi.org/10.1212/WNL. 58.2.198

Ryan, J., Fransquet, P., Wrigglesworth, J., \& Lacaze, P. (2018). Phenotypic heterogeneity in dementia: a challenge for epidemiology and biomarker studies. Frontiers in Public Health, 6, 181. https://doi.org/10.3389/fpubh.2018.00181

Schmidt-Daffy, M. (2013). Fear and anxiety while driving: differential impact of task demands, speed and motivation. Transportation Research Part F: Psychology and Behaviour, 16, 14-28. https://doi.org/10.1016/j.trf.2012.07.002

Shamay-Tsoory, S.G., Tomer, R., Berger, B.D., \& Aharon-Peretz, J. (2003). Characterization of empathy deficits following prefrontal brain damage: the role of the right ventromedial prefrontal cortex. Journal of Cognitive Neuroscience, 15(3), 324-337. https://doi. org/10.1162/089892903321593063

Spikman, J.M., Timmerman, M.E., Milders, M.V., Veenstra, W.S., \& van der Naalt, J. (2012). Social cognition impairments in relation to general cognitive deficits, injury severity, and prefrontal lesions in traumatic brain injury patients. Journal of Neurotrauma, 29(1), 101-111. https://doi.org/10.1089/neu. 2011.2084

Steigenberger, N. (2015). Emotions in sensemaking: a change management perspective. Journal of Organizational Change Management, 28(3), 432-451. https://doi.org/10.1108/JOCM05-2014-0095

Tekin, S., \& Cummings, J.L. (2002). Frontal-subcortical neuronal circuits and clinical neuropsychiatry: an update. Journal of Psychosomatic Research, 53(2), 647-654. https://doi.org/10. 1016/S0022-3999(02)00428-2

van den Berg, N.S., Huitema, R.B., Spikman, J.M., Luijckx, G.J., \& de Haan, E.H.F. (2020). Impairments in emotion recognition 
and risk-taking behavior after isolated, cerebellar stroke. Cerebellum, 19, 419-425. https://doi.org/10.1007/s12311-02001121-x

Verster, J.C., \& Roth, T. (2011). Standard operation procedures for conducting the on-the-road driving test, and measurement of the standard deviation of lateral position (SDLP). International Journal of General Medicine, 4, 359-371. https://doi.org/10. 2147/IJGM.S19639

Visser-Keizer, A.C., Westerhof-Evers, H.J., Gerritsen, M.J.J., Van der Naalt, J., \& Spikman, J.M. (2016). To fear is to gain? The role of fear recognition in risky decision making in TBI patients and healthy controls. PLOS ONE, 11(11), 1-16. https://doi.org/10. 1371/journal.pone.0166995

Vlakveld, W. (2011). Hazard Anticipation Of Young Novice Drivers Assessing And Enhancing The Capabilities Of Young Novice
Drivers To Anticipate Latent Hazards In Road And Traffic Situations. University of Groningen, SWOV Institute for Road Safety Research.

Voncken, L., Timmerman, M., Spikman, J., \& Huitema, R.B. (2018). Beschrijving van de nieuwe, Nederlandse normering van de Ekman 60 Faces Test (EFT), onderdeel van de FEEST. Tijdschrift Voor Neuropsychologie, 13(2), 143-151.

Young, A.W., Perrett, D.I., Calder, A.J., Sprengelmeyer, R., \& Ekman, P. (2002). Facial Expressions Of Emotion: Stimuli And Tests (FEEST). Burry St Edmunds, England: Thames Valley Test Company.

Zeelenberg, M., Nelissen, R.M. A., Breugelmans, S.M., \& Pieters, R. (2008). On emotion specificity in decision making: why feeling is for doing. Judgement and Decision Making, 3(1), 18-27. https://doi.org/10.1080/026999398379754 